\title{
A travel cost assessment of the demand for recreation in Swiss forests
}

\author{
Nicolas Borzykowski ${ }^{1,2}$ - Andrea Baranzini ${ }^{1}$. \\ David Maradan ${ }^{1}$
}

Received: 13 May 2016 / Accepted: 25 April 2017 / Published online: 19 July 2017 (C) The Author(s) 2017. This article is an open access publication

\begin{abstract}
This paper analyzes the demand for recreation in Swiss forests using the individual travel cost method. We apply a two-steps approach, i.e., a hurdle zerotruncated negative binomial model, that allows accounting for a large number of nonvisitors caused by the off-site phone survey and over-dispersion. Given the national scale of the survey, we group forest zones to assess consumer surpluses and travel cost elasticities for relatively homogeneous forest types. We find that forest recreation activities are travel cost inelastic and show that recreation in Swiss forests provides large benefits to the population. The most populated area is associated with greater consumer surpluses, but the lack of recreational infrastructure may cause a lower recreational benefit in some zones. For these zones, recreational benefits may be lower than costs caused by maintenance. More efficient management would require either improving recreational infrastructure thus increasing benefits, or switching the forest status from recreational to biodiversity forest hence decreasing management costs.
\end{abstract}

Keywords Travel cost method · Hurdle zero-truncated negative binomial · Forest recreation $\cdot$ Switzerland

Nicolas Borzykowski

nicolas.borzykowski@hesge.ch

1 University of Applied Sciences Western Switzerland (HES-SO), Haute École de Gestion Genève (HEG-Ge), 17 rue de la Tambourine, Carouge CH-1227, Switzerland

2 University of Neuchatel, Institute of Economic Research, 2 rue A.-L. Breguet,

Neuchatel CH-2000, Switzerland 


\section{Introduction}

Recreation is one of the many forest functions: population practices sports, observes fauna and flora, picnics, benefits from fresh air, and collects valuable resources such as mushrooms, fruits, and wild game in forests. Swiss forests cover about $30 \%$ of the country surface and the Swiss Civil Code ensures the general right to freely enjoy its recreation function. With the exception of the Swiss national park and the use of special infrastructures (tree climbing, campings...), recreation in Swiss forests is thus free. In recent decades, amenities aiming at attracting people have been installed and the development of forest leisure infrastructure continues.

Due to its public good characteristics and the absence of related markets, forest recreation is a non-market service and its demand is hence not directly observable. Therefore, economic valuation techniques have been developed to assess the demand for this particular environmental service. Revealed preferences methods and in particular the travel cost method (TCM) are particularly appropriate for the valuation of recreational sites or activities. First mentioned by Harold Hotelling in the 1940s, TCM aims at deriving the demand for a given activity using the travel costs that individuals must incur as the price and the visit frequency as the quantity. The TCM assumes that these costs are lower or equal to the benefits of a recreational site's visit, so the journey is worth it.

Based on Hotelling's idea, the TCM was developed by Clawson and Knetsch in the 1960s (Clawson et al. 1959; Clawson and Knetsch 1963). Since then, a large number of studies have used this method to assess the demands for non-marketed goods or services such as recreation (see Zandersen and Tol 2009 for a meta-analysis on forest recreation and Phaneuf and Smith (2005) for a historical review). Two different approaches have been used in the literature: zonal travel costs (Bowes and Loomis 1980) or individual travel costs (Willis and Garrod 1991). The latter, based on microdata, is more precise, but requires more resources to obtain individual travel cost information.

In this paper, we derive the implicit demand for recreation in Swiss forests using the individual TCM. Because our interview is done by phone, and thus off-site, we do not assess the use of a specific forest, but rather recreation in Swiss forests in general. Our estimates are thus forest function-specific at the regional level rather than forest-specific. Only a few studies analyze the demand for recreation on a regional scale (Bartczak et al. 2008; Garcia and Jacob 2010; Bestard and Font 2010), probably because of the forest heterogeneity. Applying TCM to value recreation at the national level indeed requires some caution. Following Garcia and Jacob (2010)'s methodology, we treat this issue by splitting Swiss forests into four coherent categories referring to Swiss geographical areas (i.e, Midland; Jura; Prealps/Alps/South grouped into the Alpine zone) and urban forests. Those categories correspond to Swiss forest zones as defined by the Swiss Federal Statistical Office. This approach allows counting visits in each forest zone and thus assessing a separate value for each of them. It is indeed likely that each forest zone attracts individuals with different preferences. Also, as respondents usually go to the closest forests and less frequently to those located further away, asking only one general question may underestimate the average travel costs and hence the benefits. Indeed, respondents could rather 
describe their habits regarding the forest they visited last and forget about the further away forests they visited longer ago.

Our off-site phone survey also implies to deal with a large number of non-visitors. We therefore use a two-steps methodology as developed by Creel and Loomis (1990) accounting for this kind of individuals. We then calculate travel cost elasticities and consumer surpluses for recreation in the Swiss forests zones.

The remainder of this paper is organized as follows: Section 2 presents the questionnaire and Section 3 the empirical approach. We provide descriptive statistics in Section 4 and results in Section 5. We discuss them in Section 6 and conclude in Section 7.

\section{Survey}

We surveyed by phone 1200 adults living in Switzerland in November and December 2014. The sample is chosen with the method of random quotas for gender, age, and geographic areas and is thus roughly representative of the Swiss population. Five days before the phone call, interviewees received a letter, which includes the map of Swiss forest zones as in Fig. 1 and gives information about Swiss forests, forests regions, and the project in general. The interview lasts about $15 \mathrm{~min}$ and is composed of four parts. ${ }^{1}$ The first one analyzes the perceptions and behaviors of the Swiss population regarding its forests and is designed to apply the individual TCM. The second part investigates the potential conflicts between the different forest functions from the population point of view. The third part submits a hypothetical scenario to apply the contingent valuation method and assess the willingness to pay for the creation of new forest reserves in Switzerland (see Borzykowski et al. 2017). The final part collects the usual socio-demographic characteristics. The questionnaire has been previously tested on a smaller scale and with focus-groups (cf. Baranzini et al. 2015; Borzykowski et al. 2015) as recommended by the literature (Phaneuf and Smith 2005).

Table 6 presents the characteristics of Swiss forest zones. The Alpine zone (Alps, Prealps, and South) accounts for about $63 \%$ of Swiss forests surface and is the largest forest zone in Switzerland. The Midland area is more densely populated and thus has a smaller forest coverage and a lower surface of forest per inhabitant, compared to the other areas. Interestingly, the proportion of private owners in the Midland is higher than in the other areas, maybe because of the ease of access and the potential higher economic returns of Midland forests. Indeed, Alpine and Jura forests are more prone to be protective rather than productive forests and their exploitation are thus more costly. This is confirmed by the wood production intensity index $\left(\mathrm{m}^{3}\right.$ of harvested wood per hectare) that is much lower in the Alps and the Jura. The types of forest are defined, among other characteristics, according to their flora composition. The percentage of conifers, which impacts the type of fauna and flora, is an important

\footnotetext{
${ }^{1}$ The full questionnaire is available upon request.
} 
decision element for individuals who would like to observe nature. Conifers can be found especially in Alpine forests, because they are located at a higher altitude.

To apply TCM, we ask how often the respondent visited each forest zone during the last 12 months. If the answer is not zero, the interview continues asking distance, means of transport, number of accompanying persons, and duration of the visit. A controversy of TCM is the multi-purpose, or incidental trips issue (Parsons et al. 1997; Loomis 2006), which can be difficult to handle. Indeed, such trips must be treated with caution, by correctly disentangling travel costs by visited sites. If the entire travel costs are attributed to the assessed site, the value of the given site would be overestimated. To deal with this issue, we require the respondent to state the distance from the very point of departure to the entrance of the forest. We provide respondents with the following example to ensure that side or incidental trips are correctly taken into account: "If I go to Zermatt for holidays and that, among other things, I walk in a forest, I must indicate the distance from Zermatt to the entrance of the forest, not from my residence."

As we deal with Swiss forests in general, it is not possible to account for substitution possibilities between forests as recommended in Parsons (2003). In addition, potential substitutes (all leisure activities) are very varied and controlling for them in an appropriate way is not practically feasible.

\section{Empirical approach}

Given that the dependent variable, the annual visit frequency, is a non-negative integer, defined on $\mathbb{N}_{+}^{*}$ only, the use of OLS is inappropriate. Indeed, OLS would allow predicting negative and/or non-integer frequency. Therefore, the literature usually considers count models such as Poisson or Negative Binomial (NB). NB is often preferred for its ability to deal with over-dispersion, a common issue with survey data and all the more with TCM data.

Simple count models allow zero frequency. However, non-visitors do not incur any travel cost, as they do not travel to forests. For them, the travel cost variable thus takes the value 0 . On the one hand, the inclusion of this type of individual pushes the estimation towards the corner $(0 ; 0)$, thus artificially decreasing estimates. On the other hand, excluding zero values is a form of sample selection, which causes nonrepresentativity. Therefore, it is sometimes necessary to allow non-visitors to have different motivations and behavior and to include them in a first-step model of participation. For example, as mentioned by Haab and McConnell (2002), non-visitors could have no interest in the site for reasons such as health and age, and hence would not be responsive to prices. The whole sample must hence pass into a first step (a hurdle, $\mathrm{H}$ ), where only visitors are selected. The behavior of the selected individuals is then modeled with Zero-Truncated Poisson (ZTP) or NB (ZTNB) models. This is the very purpose of the two-steps models, the so-called hurdle models. While ZeroInflated (ZI) models (Lambert 1992; Greene 1994) look appealing, they allow for a zero frequency, even when the hurdle is crossed. In other words, and using the example on which ZI models are based, people may choose to participate in fishing, but still catch zero fish. For forest recreation, this situation is not possible, since people 
who choose to participate in forest recreation must go at least once in a given forest. The Hurdle Zero-Truncated models (HZT) (Creel and Loomis 1990) composed of any binary choice model and a conditional truncated count model are therefore the most appropriate empirical approach in our case. It is intuitively similar to a Heckman (1979) sample selection model except for the discrete nature of the statistical distribution. The possibility to distinguish the participation from the integer level at which this participation takes place and the ability to correctly deal with overdispersion makes a case in favor of the Hurdle Zero-Truncated Negative Binomial model (HZTNB). Our analysis will thus be based on this model, following Bilgic and Florkowski (2007) and Shrestha et al. (2002). This choice will be confirmed by the ad hoc statistical tests reported in Section 5.

Our model is thus composed of (i) a binary choice model (Eq. 1) explaining the probability of participation in forest recreation $\left(\pi_{i}\right)$ and (ii) a truncated count model for the forest visit conditional frequency $\left(N V_{i} \mid N V_{i}>0\right)$ (Eq. 2).

$$
\operatorname{Pr}\left(N V_{i}>0\right)=\pi_{i}=F\left(X_{1 i}\right)
$$

Where $N V_{i}$ is the number of visits of individual $i ; X_{1}$ the matrix of independent variables explaining the probability of participation in forest recreation; and $F$ the assumed probability law.

$$
N V_{i}=f\left(T C_{i} ; X_{2 i}\right) \text { for } N V_{i}>0
$$

With $T C$ the travel cost variable; $X_{2}$ the independent variables explaining the frequency of forest visits; and $f$ the second step model distribution law.

NB count models are defined with mean $E\left(N V_{i} \mid X_{2 i}\right)=\lambda_{i}$ and variance $\operatorname{Var}\left(N V_{i} \mid X_{2 i}\right)=\lambda_{i}\left(1+\alpha \lambda_{i}\right)(\alpha$ a parameter $)$ and assume that $\ln \left(\lambda_{i}\right)=$ $T C_{i}^{\prime} \beta_{T C}+X_{2 i}^{\prime} \beta_{X_{2}}$ to introduce the explanatory variables $T C_{i}$ and $X_{2 i}$ and regression coefficients $\beta_{T C}$ and $\beta_{X_{2}}$.

After the first step, ZTNB models the annual number of visit $N V_{i}$ conditioned on the participation. It is written as follows:

$$
\operatorname{Pr}\left(N V_{i}=n v \mid X_{2 i}\right)= \begin{cases}\left(1-\pi_{i}\right) & \text { if } N V_{i}=0 \\ \pi_{i} q_{i}\left[\frac{1}{1-\left(1+\alpha \lambda_{i}\right)^{-1 / \alpha}}\right] & \text { if } N V_{i} \geq n v ; n v=1,2, \ldots\end{cases}
$$

With $q_{i}$ the usual density of the Negative Binomial law ${ }^{2}$ and $\pi_{i}$ the probability of participation derived from the first step binary choice model.

Since we value four types of forests, our design does not exactly correspond to the single-site TCM as presented in Parsons (2003). We hence first estimate a pooled model with interaction variables between the travel cost variables and a dummy for the forest zones, following Garcia and Jacob (2010). Since we observe the individuals' visiting behavior for each of the forest zones and thus have four observations per individual, we handle the pooled data as a panel. However, individuals might possess quite different preferences over the forest types and thus the number of visits to each

$$
{ }^{2} q_{i}=\operatorname{Pr}\left(N V_{i}=n v\right)=\frac{\Gamma\left(n v+\frac{1}{\alpha}\right)}{\Gamma(n v+1) \Gamma\left(\frac{1}{\alpha}\right)}\left(\frac{\frac{1}{\alpha}}{\frac{1}{\alpha}+\lambda_{i}}\right)^{\frac{1}{\alpha}}\left(\frac{\lambda_{i}}{\frac{1}{\alpha}+\lambda_{i}}\right)^{n v}, n v=1,2,3 \ldots
$$


forest zone may respond differently to the covariates. In addition, creating interaction variables for all covariates would require to present the coefficients of 32 independent variables in the first step and 32 other independent variables in the second step. We thus prefer the estimation of four separate models for each four valued forest zone, as in Cho et al. (2014), and present a simplified pooled model in the Appendix to confirm our results.

\section{Data description}

\subsection{First step: participation hurdle}

The dependent variables for the first step are the binary variables Visits: $s$, which are equal to 1 when the individual visits a given forest zone $s$. We model the probability of participating to forest recreation according to different covariates that may or may not be included in the second step. Table 1 provides descriptive statistics for the first step. From the 1200 individuals that compose our full sample, we drop 50 individuals who work in forests, as their behavior is not related to recreation. An additional 22 individuals are excluded because their answers do not make sense or were badly coded. ${ }^{3}$ Some non-responses also slightly reduce the number of observations.

Ninety-four percent of our sample go to forest at least once a year. The forest zone that is the most visited is the Alps: $40 \%$ of the sample visit it at least once a year. It is followed by the Midland zone (34\%). This is not surprising, since these zones are the most extensive forests in Switzerland. Although the Alpine zone is the least densely populated area, its special forests might attract more people than the Midland, the most populated zone.

Twenty-eight live in the French-speaking part of Switzerland (French), while $17 \%$ live in the Italian-speaking part (Italian). Forty percent of the households have children (Children) and $37 \%$ are member of or donate to an environment-friendly association (Member). The average age of our respondents is 51 (Age), 14\% of the sample has a secondary residence in Switzerland (Secondary residence) and $34 \%$ answered correctly to a question on forest growth in Switzerland and is thus well informed (Well informed).

As we do not observe the distance for non-visitors, our first step may suffer from omitted variable bias. We try to correct this missing variable with the binary variable Residence: $s$ accounting for the region of residence. Used as a proxy for distance, these variables are equal to 1 if the individual lives in the same zone $s$ as the visited forest. $^{4}$

\footnotetext{
${ }^{3}$ For example, an individual claims that she travels $500 \mathrm{~km}$ to go to an Urban forest 360 times per year.

${ }^{4}$ For some individuals, Residence is equal to 1 in more than one zone. Indeed for city-dwellers (urban residents) Residence: Urban equals to 1 along with another Residence variable, as cities necessarily belong to a larger forest zone. Also, we were unfortunately unable to disentangle individuals living in the Jura from those on the Midland for the Cantons of Vaud, Aargau, Neuchâtel, and Solothurn and some individuals in the Canton of Bern, so that the sum of the Residence variables is bigger than 1 .
} 
Table 1 Descriptive statistics for the first-step estimation

\begin{tabular}{llllll}
\hline Variable & Mean & Std. Dev. & Min. & Max. & Observations \\
\hline Visits: all zones & 0.94 & $(0.23)$ & 0 & 1 & 1075 \\
Visits: Urban & 0.17 & $(0.37)$ & 0 & 1 & 1038 \\
Visits: Midland & 0.34 & $(0.47)$ & 0 & 1 & 1010 \\
Visits: Jura & 0.16 & $(0.36)$ & 0 & 1 & 1034 \\
Visits: Alps & 0.40 & $(0.49)$ & 0 & 1 & 973 \\
French & 0.28 & $(0.45)$ & 0 & 1 & 1075 \\
Italian & 0.17 & $(0.38)$ & 0 & 1 & 1075 \\
Children & 0.40 & $(0.49)$ & 0 & 1 & 1075 \\
Member & 0.37 & $(0.48)$ & 0 & 1 & 1075 \\
Age & 50.71 & $(15.37)$ & 18 & 94 & 1075 \\
Secondary residence & 0.14 & $(0.35)$ & 0 & 1 & 1075 \\
Well informed & 0.34 & $(0.48)$ & 0 & 1 & 1075 \\
Residence: Urban & 0.70 & $(0.46)$ & 0 & 1 & 1038 \\
Residence: Midland & 0.49 & $(0.50)$ & 0 & 1 & 1010 \\
Residence: Jura & 0.29 & $(0.46)$ & 0 & 1 & 1034 \\
Residence: Alps & 0.34 & $(0.47)$ & 0 & 1 & 973 \\
\hline & & & & &
\end{tabular}

\subsection{Travel costs and second-step variables}

Travel costs supported by each individual have two components: (i) the effective travel costs $(E T C)$ (out-of-the pocket costs) and (ii) the opportunity costs of the time spent $(O C T)$. We calculate $E T C_{i}$ differentiating for the type of vehicle used in as follows:

$$
E T C_{i}= \begin{cases}\frac{D_{i} C_{P M V}}{\operatorname{Persons}_{i}} & \text { if } i \text { uses a private motor vehicle } \\ D_{i} C_{P T i} & \text { if } i \text { uses public transports } \\ 0 & \text { if } i \text { walks or rides a bike }\end{cases}
$$

with $D_{i}$ the distance in kilometers. A private motor vehicle can host several individuals; thus, costs must be divided by the number of persons who occupy the vehicle (Persons $)_{i}$ ). $C_{P M V}$ includes all costs linked with the ownership and use of a private motor vehicle: depreciation, amortization, repairs, tire wear, gasoline and insurance. It amounts to $0.73 \mathrm{CHF} / \mathrm{km}^{5}$ for an average car according to the biggest Swiss cardrivers association (TCS). The costs of public transport corresponds to the price of the ticket. To calculate $C_{P T}$, we use the per kilometer base price of public transport published every year by the Swiss public transport association (VOEV 2014). Price of public transport is decreasing with distance. According to the Swiss railway company (SBB 2015), 29\% of the Swiss population has a Half-Fare travel card and we therefore uniformly reduce $C_{P T i}$ by $14.5 \%$ to keep consistency across means of transport. ${ }^{6}$ We finally assume that individuals who walk or ride a bike do not bear

\footnotetext{
${ }^{5}$ Approximately at the time, $1 \mathrm{EUR}=1.2 \mathrm{CHF}, 1 \mathrm{USD}=1 \mathrm{CHF}$.

${ }^{6}$ The Half-Fare travel card can be purchased by any individual, irrespective of age or employment status and offers a $50 \%$ reduction on the normal fare.
} 
any effective cost. Of course, bikes and shoes do depreciate with time and usage and energy is needed to walk and ride. However, we consider that these costs are very low and that they are best estimated with 0 .

Some issues regarding the calculation of travel costs still do not raise consensus. The main one, largely discussed in the literature, is whether to include and to what extent the opportunity cost of time (OCT) spent on-site and during the journey (see Smith et al. 1983). An usual underlying assumption of TCM is that individuals are travel time-neutral. That is, they do not get utility from the time of their journey, i.e. they do not benefit from the travel time to admire the landscape or enjoy a nice discussion. Cesario and Knetsch (1976) first recommended to use a fraction of wage as OCT but this calculation supposes that individuals are relatively free to substitute leisure and work time. Feather and Shaw (1999) have developed a model to control for the imperfect leisure-work substitutability, but it comes with much complication in the empirical approach. Hence, most scholars choose to use a fraction of wage (from 25\% to 100\%) (Parsons 2003) or lower (Amoako-Tuffour and Martínez-Espiñeira 2012). A relatively new approach is to estimate the cost of time through a stated preferences approach (Ovaskainen et al. 2012). The time spent on-site is also a subject of controversy: most scholars consider that excluding OCT on-site leads to downward biasing the estimates (McConnell 1992) but others (Bockstael et al. 1987) advice not to include it, because time spent on-site is an endogenous decision.

We define the OCT as the product of the travel time $T t_{i}$ in minutes and the individual opportunity cost of time $C t_{i}$ per minute. In Eq. 5 , we calculate $C t_{i}$ as a third of the individual's income, which is what is done in Cesario and Knetsch (1976)'s seminal paper. More recently Fezzi et al. (2014) have found that 3/4 of the wage is a more reasonable approximation for the OCT. Our estimates can thus be considered as conservative.

$$
C t_{i}=\frac{1}{3} \frac{\text { Income }_{i}}{\text { Adult }_{i}} \frac{1}{1585 \cdot 60}
$$

Income $_{i}$ corresponds to the middle point of the yearly household income class declared in the survey, Adults is the number of adults in the household and 1585 is the average number of hours worked per year in Switzerland (OECD 2015). Including the time spent on-site into the $O C T_{i}$ decreases the goodness of fit and significance levels of our model. We thus decide not to include any variable accounting for the time spent on-site, as in Cho et al. (2014).

Different other specifications for the travel cost variable have also been tested. In particular, instead of the declared income variable, which reduces the available observations and sometimes lacks of reliability, we tried a fixed amount of CHF10 in Eq. 5, which approximately corresponds to a third of the median hourly wage in Switzerland, as done in Ott et al. (2005). We also tested different fractions of income as Amoako-Tuffour and Martínez-Espiñeira (2012), instead of 1/3. We finally retain the model in Eq. 5, whose coefficients were statistically significant and with the highest Pseudo $-R^{2}$.

From Eqs. 4 and 5, $T C_{i}$ is then defined as:

$$
T C_{i}=2\left(E T C_{i}+C t_{i} T t_{i}\right)
$$


Where $T t_{i}$ is the travel time and $C t_{i} T t_{i}=O C T_{i}$. Note that the right-hand-side of the equation is multiplied by 2 because individuals return after visiting the forest.

Table 2 describes the dependent variable $N V_{i}$, the $T C_{i}$ variable and other explanatory variables used in the second step of the separated models. ${ }^{7}$ Relaxes, Does sport, Observes nature and Collects resource are categorical variables identifying whether the individual relaxes, does sport, observes fauna and flora or collects resources such as wood, mushrooms, berries or hunting wild game in the forest, respectively. These activities are not mutually exclusive. Economic interest takes the value of 1 if the individual has an economic link with the forest industry and Bad memories is a variable equal to 1 if the individual has bad memories or has had bad experiences in relation with forests.

Urban forests are the most frequently visited forest zone, closely followed by Midland forests, Alpine forests and Jura forests. Again, this is not surprising, since the population density is higher in urban areas and in Midland than in Jura or the Alps. It is interesting to notice that the number of visits, conditioned to the participation (Table 2), is very different from the probability to visit a given forest zone (Table 1). In particular, people do not necessarily visit Urban forests (only 17\% do), but when they do, they visit it more often than people who visit the Alpine forests (52 times per year against 43). On the contrary, a large proportion of people visits Alpine forests $(40 \%)$, but when they do, they visit them less often than those who visit Urban forests. This could be linked with population density and travel costs. In average, Urban forests are those with the significantly lowest travel costs. They are followed by Midland forests, Jura forests and Alpine forests. It is important to notice that all travel costs variables are prone to high skewness to the right, with many individuals whose costs are low and a few whose costs are very high. The median consumer surplus may therefore be an interesting information regarding the distribution.

In the pretest of this study, Baranzini et al. (2015) applied TCM to a sample of Geneva population and assessed the average and median recreation travel costs. They find that costs incurred for recreation in forests vary between CHF247 to 583 per year and per person, when excluding and including the opportunity cost of time spent on site respectively. A similar result is found by Von Grünigen and Montanari (2014), who estimated the average travel costs to recreate in Swiss forests between CHF290 and 589. These estimates can be considered as consumer surplus lower bounds, as recreation travel costs are necessarily lower or equal to recreation benefits, which are inferred from the estimated demand. In our case, for comparison, we can calculate annual travel costs including non-visitors in the following way:

$$
\text { AnnualT } C_{i s}=N V_{i s} \cdot T C_{i s} \cdot \text { Visits }_{i s}
$$

This calculation results in CHF58 for Urban forests, CHF144 for Midland forests, CHF127 for Jura forests and CHF478 for Alpine forests. These estimates are thus slightly smaller than what is found in the recent studies on Swiss forests (Von Grünigen and Montanari 2014; Baranzini et al. 2015). We note however that existing studies consider Swiss forests as a whole, without controls for their heterogeneity.

\footnotetext{
${ }^{7}$ We provide the same descriptive statistics for the pooled data in Table 7 in the Appendix.
} 
Table 2 Descriptive statistics for the second step

\begin{tabular}{|c|c|c|c|c|c|c|}
\hline Zone & Variable & Mean & Std. Dev. & Min. & Max. & Observations \\
\hline \multirow[t]{9}{*}{ Urban } & $N V$ & 51.94 & 80.75 & 2 & 365 & 173 \\
\hline & $T C$ & 6.54 & 10.15 & 0.14 & 78.11 & 173 \\
\hline & Relaxes & 0.93 & 0.25 & 0 & 1 & 173 \\
\hline & Does sport & 0.58 & 0.50 & 0 & 1 & 173 \\
\hline & Observes nature & 0.69 & 0.46 & 0 & 1 & 173 \\
\hline & Collects resource & 0.33 & 0.47 & 0 & 1 & 173 \\
\hline & Age & 49.58 & 15.95 & 19 & 90 & 173 \\
\hline & Bad memories & 0.02 & 0.13 & 0 & 1 & 173 \\
\hline & Economic interest & 0.20 & 0.40 & 0 & 1 & 173 \\
\hline \multirow[t]{9}{*}{ Midland } & $N V$ & 46.99 & 64.08 & 1 & 365 & 343 \\
\hline & $T C$ & 9.04 & 17.91 & 0.11 & 150.21 & 343 \\
\hline & Relaxes & 0.93 & 0.26 & 0 & 1 & 343 \\
\hline & Does sport & 0.59 & 0.49 & 0 & 1 & 343 \\
\hline & Observes nature & 0.68 & 0.47 & 0 & 1 & 343 \\
\hline & Collects resource & 0.35 & 0.48 & 0 & 1 & 343 \\
\hline & Age & 49.48 & 14.61 & 18 & 93 & 343 \\
\hline & Bad memories & 0.02 & 0.14 & 0 & 1 & 343 \\
\hline & Economic interest & 0.25 & 0.43 & 0 & 1 & 343 \\
\hline \multirow[t]{9}{*}{ Jura } & $N V$ & 40.18 & 72.65 & 1 & 400 & 163 \\
\hline & $T C$ & 19.81 & 25.84 & 0.15 & 127.58 & 163 \\
\hline & Relaxes & 0.91 & 0.28 & 0 & 1 & 163 \\
\hline & Does sport & 0.61 & 0.49 & 0 & 1 & 163 \\
\hline & Observes nature & 0.76 & 0.43 & 0 & 1 & 163 \\
\hline & Collects resource & 0.36 & 0.48 & 0 & 1 & 163 \\
\hline & Age & 52.77 & 14.29 & 19 & 91 & 163 \\
\hline & Bad memories & 0.06 & 0.23 & 0 & 1 & 163 \\
\hline & Economic interest & 0.22 & 0.42 & 0 & 1 & 163 \\
\hline \multirow[t]{9}{*}{ Alps } & $N V$ & 43.1 & 70.35 & 1 & 365 & 394 \\
\hline & $T C$ & 27.07 & 47.24 & 0.11 & 352.57 & 394 \\
\hline & Relaxes & 0.94 & 0.23 & 0 & 1 & 394 \\
\hline & Does sport & 0.62 & 0.49 & 0 & 1 & 394 \\
\hline & Observes nature & 0.73 & 0.45 & 0 & 1 & 394 \\
\hline & Collects resource & 0.44 & 0.50 & 0 & 1 & 394 \\
\hline & Age & 50.34 & 13.74 & 18 & 86 & 394 \\
\hline & Bad memories & 0.03 & 0.16 & 0 & 1 & 394 \\
\hline & Economic interest & 0.28 & 0.45 & 0 & 1 & 394 \\
\hline
\end{tabular}

Almost all visitors go to forest to relax independently of the type of forest (91 to $94 \%$ ). A high proportion of people who visit Jura forests observes fauna and flora (76 
and $73 \%$ respectively) and practice sport activities (61 and 62\%, respectively). This confirms the presence of a larger biodiversity and number of sports activities in these forests, compared to Urban or Midland forest. Collection of resource is an activity that is more often undertaken in the Alps.

Only a few visitors ( 2 to $6 \%$ ) have had bad experiences with forests ${ }^{8}$ and 20 to $30 \%$ have an economic interest in the forest industry with a significantly lower proportion for the Urban forests visitors. The latter proportion is surprisingly high as we dropped individuals whose job is in forests and only $3 \%$ of the Swiss population works in the primary sector (FSO 2015).

\section{Results}

We specify the first step participation model as the following probit model.

$$
\operatorname{Pr}\left(N V_{i s}>0 \mid X_{1 i s}\right)=\operatorname{Pr}\left(\text { Visits }_{i s}=1 \mid X_{1 i s}\right)=\Phi\left(\alpha_{s}+\beta_{X_{1} s} X_{1 i s}+\varepsilon_{i s}\right)
$$

With $X_{1 i s}$ the explanatory variables described in Section 4; Visits $s_{i s}$ a dummy variable equal to 1 if the individuals visits the forest zone $s$; $\Phi$ the standard normal distribution; $\alpha_{s}$ a constant; $\beta_{X_{1} s}$ the coefficients associated with $X_{1 s}$ and $\varepsilon_{i s}$ an error term.

The second step estimation explains the annual visit frequency, given that the individual visits forest at least once a year and hence passed the first step hurdle. Since forest types are very different, it is likely that individual preferences vary in a substantive manner. We therefore estimate distinct models for each forest zone, specified as follows for the second step ${ }^{9}$ :

$$
\ln \left(\lambda_{i s}\right)=E\left[N V_{i s}\right]=a_{s}+\beta_{T C s} T C_{i s}+\beta_{X_{2} s} X_{2 i s}+u_{i s}
$$

With $a_{s}$ a constant; $\beta_{T C s}$ the coefficient associated with the $T C_{s}$ variable; $X_{2 s}$ the explanatory variables described in Section $4.2 ; \beta_{X_{2} s}$ the vector of associated coefficients and $u_{i s}$ an error term. The models specification is based on the significance levels of covariates coefficients, the joint significance Wald- $\chi^{2}$ tests, the AIC and different $R^{2}$ measures.

For all estimations, the first and second steps are estimated simultaneously, following Long and Freese (2014). Coefficients of the second step can be interpreted as semi-elasticities.

Estimation results of the separated models are presented in Table 3. We observe that, as expected, living in a given zone increases the probability of visiting the forests of this zone. People living in the French-speaking part of Switzerland are less likely to visit a Midland forest, compared to people living in the German-speaking part and the opposite is true in Jura and Alps forest. This could be explained by geographical reasons: a larger part of the Midland area is situated in the German-speaking region, while almost all Jura region is in the French part. This is not the case for Alpine forests however. People living in the Italian-speaking part of Switzerland are

\footnotetext{
${ }^{8}$ This proportion is significantly higher for Jura forest visitors.

${ }^{9} \mathrm{~A}$ pooled model is presented in the Appendix.
} 
Table 3 Results of the HZTNB estimation

\begin{tabular}{|c|c|c|c|c|}
\hline & Urban & Midland & Jura & Alps \\
\hline \multicolumn{5}{|l|}{ Visits $_{S}$ (Participation) } \\
\hline Residence $_{s}$ & $\begin{array}{l}0.67 * * * \\
(0.12)\end{array}$ & $\begin{array}{l}0.54 * * * \\
(0.095)\end{array}$ & $\begin{array}{l}1.22 * * * \\
(0.12)\end{array}$ & $\begin{array}{l}1.13 * * * \\
(0.13)\end{array}$ \\
\hline French & $\begin{array}{l}-0.13 \\
(0.11)\end{array}$ & $\begin{array}{l}-0.33^{* * * *} \\
(0.099)\end{array}$ & $\begin{array}{l}0.60 \text { *** } \\
(0.12)\end{array}$ & $\begin{array}{l}0.19 * \\
(0.11)\end{array}$ \\
\hline Italian & $\begin{array}{l}-0.31 * * \\
(0.14)\end{array}$ & $\begin{array}{l}-0.85^{* * *} \\
(0.15)\end{array}$ & $\begin{array}{l}-0.58^{* *} \\
(0.29)\end{array}$ & $\begin{array}{l}-0.13 \\
(0.15)\end{array}$ \\
\hline Children & $\begin{array}{l}0.19 * \\
(0.11)\end{array}$ & $\begin{array}{l}0.20 * * \\
(0.099)\end{array}$ & $\begin{array}{l}0.41 * * * \\
(0.13)\end{array}$ & $\begin{array}{l}-0.20^{*} \\
(0.10)\end{array}$ \\
\hline Member & $\begin{array}{l}0.21 * * \\
(0.099)\end{array}$ & $\begin{array}{l}-0.0056 \\
(0.089)\end{array}$ & $\begin{array}{l}0.36^{* * *} \\
(0.11)\end{array}$ & $\begin{array}{l}0.14 \\
(0.093)\end{array}$ \\
\hline Age & $\begin{array}{l}-0.027 * \\
(0.015)\end{array}$ & $\begin{array}{l}0.013 \\
(0.015)\end{array}$ & $\begin{array}{l}0.019 \\
(0.020)\end{array}$ & $\begin{array}{l}0.059 * * * \\
(0.016)\end{array}$ \\
\hline$A g e^{2}$ & $\begin{array}{l}0.00025^{*} \\
(0.00015)\end{array}$ & $\begin{array}{l}-0.00015 \\
(0.00015)\end{array}$ & $\begin{array}{l}-0.000071 \\
(0.00020)\end{array}$ & $\begin{array}{l}-0.00064 * * * \\
(0.00016)\end{array}$ \\
\hline Secondary Residence & $\begin{array}{l}-0.12 \\
(0.15)\end{array}$ & $\begin{array}{l}-0.16 \\
(0.13)\end{array}$ & $\begin{array}{l}-0.15 \\
(0.18)\end{array}$ & $\begin{array}{l}0.54 * * * \\
(0.13)\end{array}$ \\
\hline Well informed & $\begin{array}{l}-0.037 \\
(0.10)\end{array}$ & $\begin{array}{l}-0.040 \\
(0.091)\end{array}$ & $\begin{array}{l}0.20^{*} \\
(0.12)\end{array}$ & $\begin{array}{l}0.42^{* * *} \\
(0.093)\end{array}$ \\
\hline Constant & $\begin{array}{l}-0.86^{* *} \\
(0.38)\end{array}$ & $\begin{array}{l}-0.76^{* * *} \\
(0.37)\end{array}$ & $\begin{array}{l}-2.86^{* * * *} \\
(0.52)\end{array}$ & $\begin{array}{l}-2.06^{* * * *} \\
(0.39)\end{array}$ \\
\hline \multicolumn{5}{|l|}{$N V_{s}$ (Frequency) } \\
\hline$T C$ & $\begin{array}{l}-0.0089 \\
(0.016)\end{array}$ & $\begin{array}{l}-0.0089^{* *} \\
(0.0044)\end{array}$ & $\begin{array}{l}-0.040 * * * \\
(0.0046)\end{array}$ & $\begin{array}{l}-0.014 * * * \\
(0.0019)\end{array}$ \\
\hline Relaxes & $\begin{array}{l}0.58^{*} \\
(0.31)\end{array}$ & $\begin{array}{l}0.18 \\
(0.23)\end{array}$ & $\begin{array}{l}-0.53 \\
(0.50)\end{array}$ & $\begin{array}{l}0.31 \\
(0.28)\end{array}$ \\
\hline Does sport & $\begin{array}{l}0.45^{*} \\
(0.27)\end{array}$ & $\begin{array}{l}0.48 * * * \\
(0.17)\end{array}$ & $\begin{array}{l}0.26 \\
(0.28)\end{array}$ & $\begin{array}{l}0.33^{*} \\
(0.17)\end{array}$ \\
\hline Observes nature & $\begin{array}{l}-0.0048 \\
(0.23)\end{array}$ & $\begin{array}{l}0.027 \\
(0.17)\end{array}$ & $\begin{array}{l}0.30 \\
(0.26)\end{array}$ & $\begin{array}{l}0.44 * * \\
(0.18)\end{array}$ \\
\hline Collects resource & $\begin{array}{l}-0.14 \\
(0.24)\end{array}$ & $\begin{array}{l}0.28^{*} \\
(0.15)\end{array}$ & $\begin{array}{l}0.15 \\
(0.23)\end{array}$ & $\begin{array}{l}0.25 \\
(0.16)\end{array}$ \\
\hline Age & $\begin{array}{l}0.022 * * * \\
(0.0076)\end{array}$ & $\begin{array}{l}0.014 * * \\
(0.0061)\end{array}$ & $\begin{array}{l}0.0026 \\
(0.0077)\end{array}$ & $\begin{array}{l}0.0021 \\
(0.0057)\end{array}$ \\
\hline Economic Interest & $\begin{array}{l}0.060 \\
(0.30)\end{array}$ & $\begin{array}{l}0.18 \\
(0.17)\end{array}$ & $\begin{array}{l}0.48^{* *} \\
(0.24)\end{array}$ & $\begin{array}{l}0.37 * * \\
(0.16)\end{array}$ \\
\hline Bad Memories & $\begin{array}{l}-1.66^{* * *} \\
(0.23)\end{array}$ & $\begin{array}{l}0.33 \\
(0.54)\end{array}$ & $\begin{array}{l}0.20 \\
(0.53)\end{array}$ & $\begin{array}{l}0.25 \\
(0.52)\end{array}$ \\
\hline Constant & $\begin{array}{l}2.05 * * * \\
(0.56)\end{array}$ & $\begin{array}{l}2.49 * * * \\
(0.41)\end{array}$ & $\begin{array}{l}3.68 * * * \\
(0.78)\end{array}$ & $\begin{array}{l}2.68 * * * \\
(0.46)\end{array}$ \\
\hline
\end{tabular}


Table 3 (continued)

\begin{tabular}{lllll}
\hline & Urban & Midland & Jura & Alps \\
\hline Observations (total) & 1038 & 1010 & 1034 & 973 \\
Non-zero observations & 173 & 343 & 163 & 394 \\
$\ln (\alpha)$ & $0.60 * * *$ & $0.40 * * *$ & $0.54 * * *$ & $0.57 * * *$ \\
Vuong stat. for ZTNB over ZINB & 0.55 & -0.41 & $-5.26 * * *$ & $-2.46 * * *$ \\
Accuracy & $70 \%$ & $46 \%$ & $75 \%$ & $41 \%$ \\
\hline
\end{tabular}

Heteroskedasticity-robust standard errors in parentheses

$* p<0.1, * * p<0.05$, *** $p<0.01$

less prone to visit an Urban, Midland or Jura forest, compared to people living in the German-speaking part. This is not surprising since the Italian-speaking part is situated in the Alps, and is further away from Midland and Jura forests.

Having a child increases the probability to visit a forest zone, except for the Alps, probably because Alpine forests are steeper and less accessible. Membership to an environment friendly organization is associated with a greater participation in all forest zones, except Midland forests. Interestingly, as shown by the $A g e$ and $A g e^{2}$ variables, the age first increases and then decreases the probability of visiting Alpine forests, while we observe the opposite in Urban forests. A significant quadratic effect of age is also found in Von Grünigen and Montanari (2014). Ease of access is probably the main explanation. Indeed Urban forests are usually closer by and more accessible, but interest in visiting an Urban forest might only grow after a certain age. Alpine forests usually require a certain ability to do sports or move which might be lower after a threshold. This result may also be due to a change in preferences with age.

Having a secondary residence increases the probability to visit an Alpine forest, but has no effect on other forest zones. We expected this result, since most secondary residences are located in the Alps.

Finally, being well informed increases the participation in Alpine forests. This may be due to reverse causality as those who visit Alpine forests are more likely to notice a forest growth, because this forest zone has grown the most.

According to the second step estimation, all travel cost variables have the expected negative sign, but the effect of travel cost is not statistically significant for Urban forests. The latter result is unsurprising, given that the travel cost to visit Urban forests is generally low and relatively homogeneous among individuals. In addition, in the urban environment, individuals have many other leisure opportunities, which explains the statistically insignificant $T C$ coefficient (Bertram and Larondelle 2017).

The coefficients associated with the activities undertaken in forests show the type of forests preferred for given activities. Urban forests are more visited for relaxation and doing sports, Midland forests for collection of resources and sport and Alpine forests are used for sports or observation of nature. These results show the importance of Urban forests to escape the city stress and the importance of Alpine forests for sports activities such as hiking and skiing. Recent surveys have shown that $44 \%$ 
of the Swiss population hikes and 36\% skies in the mountains (Lamprecht et al. 2014), which can explain the positive impact of Does sport on the number of visits in Alpine forests. The productive role of Midland forests is also confirmed by the positive coefficient associated with the Collects resource variable.

Conditioned on participation, age has a positive impact on the number of visits for Urban and Midland forests. Having bad memories linked with forests decreases the number of visits in Urban forests, but there are very few individuals in this case. Finally, having economic interests in the forest industry, as expected, increases the number of visits to forests in the Jura and the Alps.

The statistically significant $\ln (\alpha)$, which measures the likelihood-ratio test for over-dispersion, give clear evidence in favor of the use of the Negative Binomial models over the Poisson models. Vuong tests also confirm the choice to use a hurdle model, rather than a simple NB model. ${ }^{10}$ To confirm our choice of ZTNB over ZINB $^{11}$, we run another Vuong test, as suggested in Long and Freese (2014, pp. 549551 ) and find that it does not provide any evidence that the ZTNB fits better than the ZINB for Urban and Midland forests. However, it does for Jura and Alps forests. The choice of the HZTNB is therefore justified.

The computation of the Vuong test also require to calculate the accuracy of predicted probabilities, which ranges between 41 and $70 \%$ depending of the forest zone.

We provide the estimation results of a pooled model in Table 8 in the Appendix. For this model, the coefficients associated with the dummies Urban, Midland and Jura, which indicate the location of the forest, have a negative impact on the probability to participate in forest recreation, compared to the Alps forests. This is unsurprising since the Alps forests are the most visited forests. The statistical significance of these variables is a confirmation that preferences are different across forest zones and is a justification to use the separate models. Indeed, while this pooled model has more statistical power thanks to the higher number of observations, coefficients represent an average effect of the covariates across forest zones. A likelihood-ratio test on the first step also rejects the hypothesis that the coefficients are the same across forest zones (LR stat. $(24)=312.3, p$ value $<0.01$ ). The separated models are thus able taking into account more heterogeneity. In addition, the predicted probabilities accuracy scores higher for some separate estimations (53\% for the pooled model against 41 to $70 \%$ for the separated models). We therefore prefer the separated models and hereafter present their cost-elasticities and consumer surplus. It is worth noting, however, that coefficients of the second step of the pooled model are comparable to those resulting from the separated models and that the Vuong test on the pooled model also provides evidence that the ZTNB fits better than the ZINB.

\subsection{Mean travel costs and elasticities}

Cost elasticities $\left(\varepsilon_{s}^{T C}\right)$ represent changes in visit frequencies (in percent) for a percent change in travel costs, everything else kept constant. To get elasticities, we calculate

\footnotetext{
${ }^{10}$ This test is provided with the ZINB estimation using the vuong option on Stata14.

${ }^{11}$ The ZINB results are available upon request.
} 
Table 4 Travel costs elasticities

\begin{tabular}{lllll}
\hline & Urban & Midland & Jura & Alps \\
\hline$\varepsilon_{s}^{T C}$ & -0.58 & $-0.08^{* *}$ & $-0.80^{* * *}$ & $-0.38^{* * *}$ \\
& $(0.10)$ & $(0.04)$ & $(0.09)$ & $(0.05)$ \\
Mean $T C_{s}$ & 6.5 & 9.0 & 19.8 & 27.1 \\
Observations & 173 & 343 & 163 & 394 \\
\hline
\end{tabular}

Standard errors calculated with the Delta method in parentheses $* p<0.1$, ** $p<0.05$, *** $p<0.01$

the average marginal effects with the prediction function from the estimates. ${ }^{12}$ Cost elasticities from the separated models are shown in Table $4 .{ }^{13}$

Jura forests are the most sensitive to an increase in travel cost, while Urban forests are not sensitive since the effect of $T C$ on $N V$ is not significant. A cost increase of $1 \%$ would decrease visit frequency to Jura forests by $0.8 \%$, this impact being 10 times lower in Midland forests. However, travel costs associated with Midland forest are on average lower than those associated with Jura forests: mean TC is CHF9 per visit in Midland against CHF20 in Jura. In absolute terms, a 1\% increase in travel costs for Midland corresponds on average to $\mathrm{CHF0.09}$ which would decrease annual frequency by 0.04 times. For Jura forests, a $1 \%$ increase in travel costs is equal to a CHF0.19 increase which would decrease frequency by 0.32 times. In the Alps, a CHF0.20 increase is linked with a 0.16 times decrease in frequency.

\subsection{Consumer surplus}

Marshallian Consumer Surplus $(C S)$ is the area between the demand curve and the price. The average unconditional individual annual $C S$ for forest zone $s$ is hence:

$$
C S_{i s}=-\pi_{i s} \frac{\lambda_{i s}}{\beta_{T C s}}
$$

From (9), as in Creel and Loomis (1990), the surplus per visit becomes:

$$
\frac{C S_{i s}}{\pi_{i s} \lambda_{i s}}=-\frac{1}{\beta_{T C S}}
$$

With $\pi_{i s}$ the probability of visiting a given forest, $\lambda_{i s}$ the parameter of the NB law and $\beta_{T C s}$ the coefficient of the travel cost variables.

We calculate the mean conditional annual $C S$ by multiplying the $C S$ per visit by the average annual frequency. This annual $C S$ is then multiplied by the proportion of visitors to obtain the annual unconditional $C S$. The consumer surpluses from the separated models are presented in Table $5 .{ }^{14}$

\footnotetext{
${ }^{12}$ These elasticities can be easily obtained using the margins, eyex command in Stata14.

${ }^{13}$ Cost elasticities from the pooled model are presented in Table 9 in the Appendix. We observe that this model provides slightly lower elasticities estimates. In particular, the Jura and Alpine forests are less sensitive to a travel cost increase with this approach.

${ }^{14}$ For the pooled model, consumer surpluses, presented in Table 10, in the Appendix, are comparable to the $C S$ from the separated models.
} 
Table 5 Individual consumer surpluses $(C S)$

\begin{tabular}{|c|c|c|c|c|}
\hline & Urban & Midland & Jura & Alps \\
\hline CS per visit & $\begin{array}{l}112.8 \\
{[-284 ; 510]}\end{array}$ & $\begin{array}{l}112.7 * * \\
{[4 ; 222]}\end{array}$ & $\begin{array}{l}24.7 * * * \\
{[19 ; 30]}\end{array}$ & $\begin{array}{l}71.6^{* * * *} \\
{[53 ; 90]}\end{array}$ \\
\hline Conditional annual $C S$ & $\begin{array}{l}5859 \\
{[-14771 ; 26489]}\end{array}$ & $\begin{array}{l}5293 * * \\
{[166 ; 10420]}\end{array}$ & $\begin{array}{l}994 * * * \\
{[772 ; 1215]}\end{array}$ & $\begin{array}{l}3084 * * * \\
{[2273 ; 3896]}\end{array}$ \\
\hline Median conditional annual $C S$ & $\begin{array}{l}2256 \\
{[-5688 ; 10201]}\end{array}$ & $\begin{array}{l}2704 * * \\
{[85 ; 5322]}\end{array}$ & $\begin{array}{l}297 * * * \\
{[231 ; 363]}\end{array}$ & $\begin{array}{l}1431 * * * \\
{[1055 ; 1808]}\end{array}$ \\
\hline Unconditional annual $C S$ & $\begin{array}{l}977 \\
{[-2462 ; 4415]}\end{array}$ & $\begin{array}{l}1798 * * \\
{[57 ; 3539]}\end{array}$ & $\begin{array}{l}157 * * * \\
{[122 ; 192]}\end{array}$ & $\begin{array}{l}1249 * * * \\
{[920 ; 1577]}\end{array}$ \\
\hline Median unconditional annual $C S$ & $\begin{array}{l}376 \\
{[-948 ; 1700]}\end{array}$ & $\begin{array}{l}918 \\
{[29 ; 1808]}\end{array}$ & $\begin{array}{l}47 \\
{[36 ; 57]}\end{array}$ & $\begin{array}{l}580 \\
{[427 ; 732]}\end{array}$ \\
\hline Mean density $(C S / 100 h a)$ & n.a. & $0.80 * *$ & $0.067 * * *$ & $0.16^{* * *}$ \\
\hline Observations & 173 & 343 & 163 & 394 \\
\hline
\end{tabular}

95\% confidence intervals in brackets

Standard deviations in parentheses

$* p<0.1, * * p<0.05$, *** $p<0.01$

n.a. statistics about Urban forests size is not available

The mean conditional annual $C S$ corresponds to the mean recreational benefits from forests obtained by visitors only, while the mean unconditional annual $C S$ refers to mean benefits extrapolated to the whole population according to the proportion of visitors.

Midland forests is the most valued forest zone. The $C S$ per visit in this zone scores higher than in Alpine forests, but the difference is not statistically significant. The effect of secondary residences may reduce travel cost per visit and hence the $C S$. However, the choice of the secondary residence may also be driven by the forest proximity. Annual unconditional $C S$ is on average CHF1798 in Midland forests and CHF1249 in Alpine forests. On the contrary, Jura forests are significantly less valued for their recreational activities (CHF157 per year). In terms of recreational density (unconditional annual consumer surplus per $100 \mathrm{ha}$ ), Midland forests are much more intensively valued, which reflects the population density and the high $C S$ per visit in this zone. Jura forests are again less attractive than other forest zones for recreation purposes. This may be due to preferences, but could also be explained by a lower density of infrastructures and roads network or a lower number of incidental activities opportunities.

\section{Discussion}

Baranzini and Rochette (2008) assessed the annual average benefit from the Pfyn pine forest in Switzerland between CHF1135 and 1540 per individual. This singlesite valuation survey has the particularity of dealing with a relatively homogeneous forest. However, the on-site nature of the survey only selects visitors. In addition, more frequent visitors are likely to be over-represented in the sample, as the probability to survey them is higher than for one-time visitors. This type of survey thus 
suffers from both truncation and endogenous stratification. An OLS estimation cannot be legitimate in this case either. Their estimates could however be compared with the conditional consumer surplus in Alpine forests. We observe that our estimates are higher. However, Baranzini and Rochette (2008) calculated the opportunity cost of time as a fourth of annual income (against a third here) and consider that Swiss work 2000 hours a year (against 1585 here). Also, our estimates represent the consumer surplus for the entire forest zone, from which the Pfyn pine forest only represents a tiny part.

The meta-analysis of Zandersen and Tol (2009) finds a consumer surplus between EUR0.66 and 112 per trip in European forests, with a median of 4.52, GDP per capita and population density playing a significant role. Because Switzerland is one of the richest European country in terms of GDP per capita and is very densely populated, it is not surprising that our CS are higher than the international literature. We have also seen that Midland forests, the most densely populated area are highly valued, which confirms this intuition.

Costs related to recreation in forests depend on the intensity of recreational activities. Road maintenance and securing forests imply higher costs and economic shortfalls for the forest industry. According to Bernasconi et al. (2003), in the Canton of Bern, ${ }^{15}$ these costs amounted from CHF190 to CHF3970 per inhabitant, per year depending on the forest's importance in terms of recreation and CHF418 on average. We observe that estimated $C S$ exceed the average costs, except for Jura forests, whose costs induced by recreational activities are higher. In Jura, forest management based on cost-benefit analyses for recreation would require either improving recreational infrastructure to increase the associated benefits in some forests, or switching some forests status from recreational to biodiversity forest, which would decrease the cost associated with recreation infrastructure. For example, some recreational forests may be turned into natural reserves, in which access could be limited. This change would foster biodiversity and hence increase the non-use or option values of these forests (see Borzykowski et al. 2017). In addition, costs of forest management would decrease.

\section{Conclusion}

We model the demand for recreation in Swiss forests using the individual TCM for different forest zones in Switzerland and derive travel costs elasticities and consumer surpluses. Our methodology takes into account a large number of non-visitors inherent from our off-site national phone survey, as well as over-dispersion thanks to the hurdle zero-truncated-negative-binomial model. Our results are in line with the recent TCM literature in Switzerland and Europe and show that recreation in Swiss forests provides large benefits to the population. Recreation in forest is travel cost inelastic, but its value differs across forest zones. We find that the most populated area

\footnotetext{
${ }^{15}$ The Canton of Bern contains all types of forest we analyzed.
} 
is associated with greater consumer surpluses and observe that benefits from recreation in Jura forests are on average lower than management costs. For this zone, some forests could be turned from recreational forests to forest reserves, to foster biodiversity. In addition to reducing the costs of forest management, this policy would increase the non-use and option values of these forests.

Our methodology leads to a probable overestimation of consumer surplus because we were not able to account for close substitutes nor recreational activities in bordering forests. In addition, the off-site nature of the survey could introduce some uncertainty : because observations are based on declarations regarding past visits and not actual visits, respondents may be subject to strategic issues or unable to remember. However, on-site surveys also ask this type of questions and hence suffer from this kind of uncertainty as well. As we also run a contingent valuation in the same survey, an extension of this paper would be to analyze differences across valuation methods for the same individuals.

Acknowledgements We would like to thank Milad Zarin-Nejadan for the useful comments and suggestions and two anonymous reviewers, who greatly helped improving the paper. We bear the sole responsibility of all remaining errors. Financial support from the Swiss National Research Program 66 "Resource Wood" is acknowledged.

Open Access This article is distributed under the terms of the Creative Commons Attribution 4.0 International License (http://creativecommons.org/licenses/by/4.0/), which permits unrestricted use, distribution, and reproduction in any medium, provided you give appropriate credit to the original author(s) and the source, provide a link to the Creative Commons license, and indicate if changes were made.

\section{Appendix}

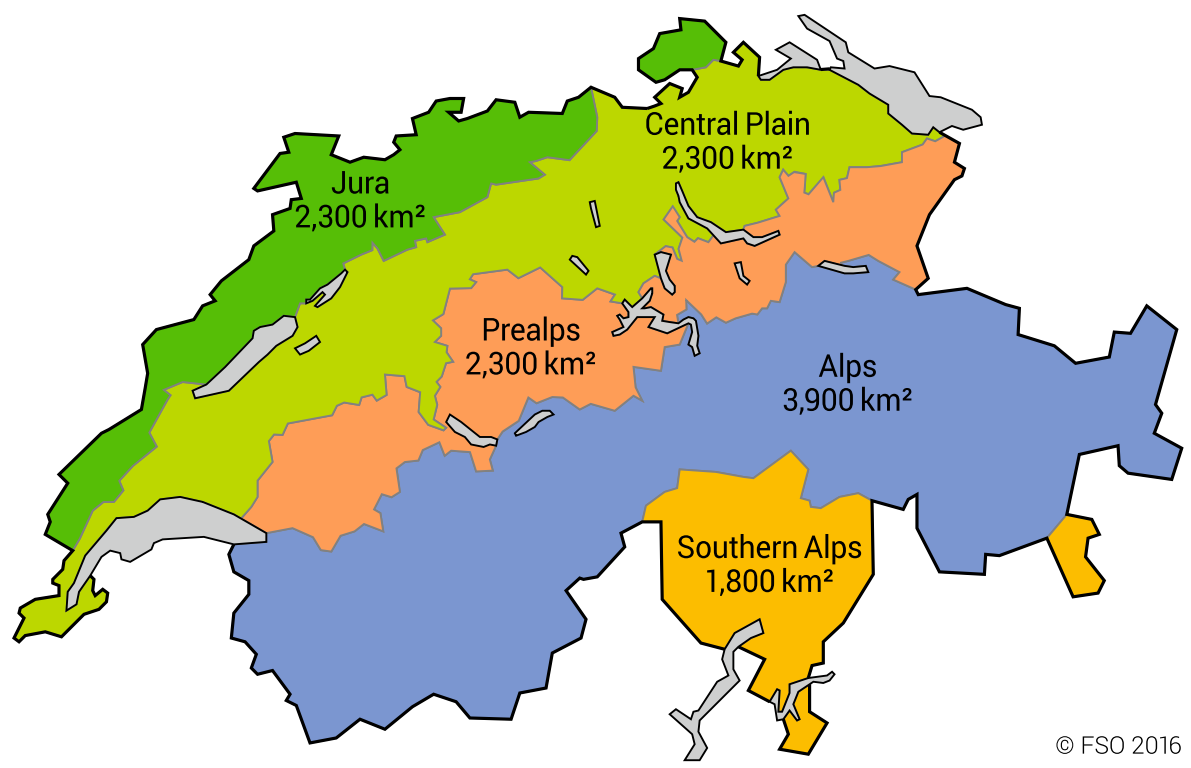

Fig. 1 Map of the Swiss forest zones. Source: FSO (2016) 
Table 6 Description of forest zones. Source: FOEN (2014) and FSO (2015)

\begin{tabular}{|c|c|c|c|c|c|c|c|c|c|}
\hline Forest zone & $\begin{array}{l}\text { Total } \\
\mathrm{km}^{2}\end{array}$ & $\begin{array}{l}\text { Forest } \\
\mathrm{km}^{2}\end{array}$ & $\begin{array}{l}\text { Forest } \\
\%\end{array}$ & $\begin{array}{l}\text { Pop. } \\
1000 h a b\end{array}$ & $\begin{array}{l}\text { Forest/cap } \\
a / h a b\end{array}$ & $\begin{array}{l}\text { Private } \\
\%\end{array}$ & $\begin{array}{l}\text { Conifers } \\
\%\end{array}$ & $\begin{array}{l}\text { Forest dens. } \\
m^{3} / h a\end{array}$ & $\begin{array}{l}\text { Prod. intens } \\
m^{3} / h a\end{array}$ \\
\hline Switzerland & 41,285 & 12,582 & 30 & 7204 & 18 & 29 & 67 & 350 & 3.8 \\
\hline Jura & $\begin{array}{l}4766 \\
(11.5)\end{array}$ & $\begin{array}{l}2341 \\
(18.6)\end{array}$ & 49 & $\begin{array}{l}1023 \\
(14.2)\end{array}$ & 23 & 22 & 53 & 378 & 4.7 \\
\hline Midland & $\begin{array}{l}9836 \\
(23.8)\end{array}$ & $\begin{array}{l}2262 \\
(18.0)\end{array}$ & 23 & $\begin{array}{l}4304 \\
(59.7)\end{array}$ & 5 & 45 & 51 & 386 & 7.5 \\
\hline $\begin{array}{l}\text { Alps, Prealps } \\
\text { and South }\end{array}$ & $\begin{array}{l}26 ' 684 \\
(64.6)\end{array}$ & $\begin{array}{r}\text { 7'979 } \\
(63.4)\end{array}$ & 30 & $\begin{array}{l}1 ' 880 \\
(26.1)\end{array}$ & 42 & 27 & 75 & 332 & 2.5 \\
\hline
\end{tabular}

Percentage of total in parentheses

\section{Pooled model}

The pooled model differs from the separated models by the inclusion of the dummy variables Urban, Midland and Jura, to indicate the specific forest zone and by the absence of the Residence variable in the first step. We select the following second step specification for the pooled model:

$$
\begin{aligned}
& \ln \left(\lambda_{i}\right)=E\left[N V_{i}\right]=a+\beta_{T C_{\text {Urban }}} T C \times \operatorname{Urban}_{i}
\end{aligned}
$$

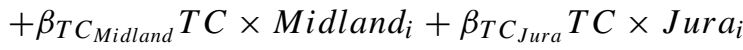

$$
\begin{aligned}
& +\beta_{T C_{\text {Alps }}} T C \times \text { Alps }_{i}+\beta_{X_{2}} X_{2 i}+u_{i}
\end{aligned}
$$

With $a$ a constant; $T C \times s$ the interaction variables with each forest zone $s$ and $\beta_{T C_{S}}$ the associated coefficients; $X_{2 i}$ the explanatory variables for the second step, $\beta_{X_{2}}$ the associated coefficients and $u$ an error term.

We handle the data as a panel, since we have 4 observations per individual (one observation per forest zone). After dropping non-complete observations, the pooled data contains 829 individuals, who visit 1.3 forest zones in average. We therefore

Table 7 Descriptive statistics for the second step (pooled)

\begin{tabular}{llllll}
\hline Variable & Mean & Std. Dev. & Min. & Max. & Observations \\
\hline$N V$ & 45.32 & 70.58 & 1 & 400 & 1073 \\
$T C_{\text {Urban }}$ & 1.06 & 4.73 & 0 & 78.11 & 1073 \\
$T C_{\text {Midland }}$ & 2.89 & 10.96 & 0 & 150.21 & 1073 \\
$T C_{\text {Jura }}$ & 3.01 & 12.31 & 0 & 127.58 & 1073 \\
$T C_{\text {Alps }}$ & 9.94 & 31.44 & 0 & 352.57 & 1073 \\
Relaxes & 0.93 & 0.25 & 0 & 1 & 1073 \\
Does sport & 0.60 & 0.49 & 0 & 1 & 1073 \\
Observes nature & 0.71 & 0.453 & 0 & 1 & 1073 \\
Collects resource & 0.38 & 0.49 & 0 & 1 & 1073 \\
Age & 50.31 & 14.5 & 18 & 93 & 1073 \\
Economic interest & 0.25 & 0.43 & 0 & 1 & 1073 \\
Bad memories & 0.028 & 0.17 & 0 & 1 & 1073 \\
& & & & &
\end{tabular}


Table 8 Results of the HZTNB estimation for the pooled models

\begin{tabular}{|c|c|c|}
\hline Visits $_{S}$ (Participation) & Coef. & (Std. Err.) \\
\hline Urban & $-0.76^{* * *}$ & $(0.063)$ \\
\hline Midland & $-0.18 * * *$ & $(0.059)$ \\
\hline Jura & $-0.81 * * *$ & $(0.064)$ \\
\hline French & 0.0646 & $(0.051)$ \\
\hline Italian & $-0.18 * * *$ & $(0.067)$ \\
\hline Children & $0.10 *$ & $(0.052)$ \\
\hline Member & $0.12 * *$ & $(0.047)$ \\
\hline Age & 0.0070 & $(0.0081)$ \\
\hline$A g e^{2}$ & -0.000068 & $(0.000080)$ \\
\hline Secondary Residence & -0.0021 & $(0.067)$ \\
\hline Well informed & $0.10 * *$ & $(0.048)$ \\
\hline Constant & $-0.45^{* *}$ & $(0.20)$ \\
\hline \multicolumn{3}{|l|}{$N V_{s}$ (Frequency) } \\
\hline$T C_{U r b a n}$ & 0.0011 & $(0.014)$ \\
\hline$T C_{\text {Midland }}$ & $-0.0099 * *$ & $(0.0046)$ \\
\hline$T C_{J u r a}$ & $-0.041^{* * *}$ & $(0.0038)$ \\
\hline$T C_{A l p s}$ & $-0.015^{* * *}$ & $(0.0018)$ \\
\hline Relaxes & 0.11 & $(0.19)$ \\
\hline Does sport & $0.39 * * *$ & $(0.10)$ \\
\hline Observes nature & $0.19 *$ & $(0.11)$ \\
\hline Collects resource & $0.16^{*}$ & $(0.093)$ \\
\hline Age & $0.0094 * * *$ & $(0.0034)$ \\
\hline Economic Interest & $0.27 * * *$ & $(0.10)$ \\
\hline Bad Memories & 0.18 & $(0.31)$ \\
\hline Constant & $2.77 * * *$ & $(0.28)$ \\
\hline Observations (total) & 3800 & \\
\hline Non-zero observations & $1073^{a}$ & \\
\hline $\ln (\alpha)$ & $0.55 * * *$ & \\
\hline Vuong stat. for ZTNB over ZINB & $-6.79 * * *$ & \\
\hline Accuracy & $53 \%$ & \\
\hline
\end{tabular}

a 829 individuals, 1.3 observations per individual on average Heteroskedasticity-robust standard errors in parentheses $* p<0.1, * * p<0.05$, *** $p<0.01$

analyze the results from 1073 observations that passed the hurdle. We run the usual Hausman test to decide between fixed or random effects and do not reject random effects $(p$ value $=0.13$ ). To test for random effects, we then apply the Breusch-Pagan LM test and do not reject the null hypothesis of no random effects. A simple pooled model (i.e., without random, nor fixed effects), presented in Table 8, is therefore the most appropriate. 
Table 9 Travel costs elasticities from the pooled model

\begin{tabular}{lllll}
\hline & Urban & Midland & Jura & Alps \\
\hline$\varepsilon_{s}^{T C}$ & 0.0012 & $-0.03^{* *}$ & $-0.12^{* * *}$ & $-0.14^{* * *}$ \\
& $(0.02)$ & $(0.01)$ & $(0.01)$ & $(0.02)$ \\
Mean $T C_{s}$ & 6.5 & 9.0 & 19.8 & 27.1 \\
Observations & & & 1073 & \\
\hline
\end{tabular}

Standard errors calculated with the Delta method in parentheses $* p<0.1$, ** $p<0.05$, *** $p<0.01$

Table 10 Individual Consumer Surpluses $(C S)$ from the pooled model

\begin{tabular}{lllll}
\hline & Urban & Midland & Jura & Alps \\
\hline CS per visit & n.a. & $101.3^{* *}$ & $24.6^{* * *}$ & $69.01 * * *$ \\
Observations & & {$[8 ; 194]$} & {$[20 ; 29]$} & {$[52 ; 86]$} \\
\hline
\end{tabular}

$95 \%$ confidence intervals calculated with the Delta method in brackets $* p<0.1, * * p<0.05$, *** $p<0.01$

NB: Since the travel cost elasticity is positive for urban forests, we do not provide the consumer surplus for urban forest

\section{References}

Amoako-Tuffour, J., \& Martínez-Espiñeira, R. (2012). Leisure and the net opportunity cost of travel time in recreation demand analysis: an application to Gros Morne national park. Journal of Applied Economics, 15(1), 25-49.

Baranzini, A., Borzykowski, N., \& Maradan, D. (2015). La forêt vue par les Genevois : perceptions et valeurs économiques de la forêt. Schweizerische Zeitschrift für Forstwesen, 166, 306-313.

Baranzini, A., \& Rochette, D. (2008). La demande des usages récréatifs pour un parc naturel. Economie rurale (4), 55-70.

Bartczak, A., Lindhjem, H., Navrud, S., Zandersen, M., \& Żylicz, T. (2008). Valuing forest recreation on the national level in a transition economy: The case of Poland. Forest Policy and Economics, 10(7), $467-472$.

Bernasconi, A., Mohr, C., \& Weibel, F. (2003). Herleitung von Grundlagen zur Kostenermittlung im Erholungswald am Fallbeispiel Region Bern. Technical report, Federal Office for the Environment.

Bertram, C., \& Larondelle, N. (2017). Going to the woods is going home: Recreational benefits of a larger urban forest site-a travel cost analysis for Berlin, Germany. Ecological Economics, 132, 255-263.

Bestard, A.B., \& Font, A.R. (2010). Estimating the aggregate value of forest recreation in a regional context. Journal of Forest Economics, 16(3), 205-216.

Bilgic, A., \& Florkowski, W.J. (2007). Application of a hurdle negative binomial count data model to demand for bass fishing in the Southeastern United States. Journal of Environmental Management, 83(4), 478-490.

Bockstael, N.E., Strand, I.E., \& Hanemann, W.M. (1987). Time and the recreational demand model. American Journal of Agricultural Economics, 69(2), 293-302.

Borzykowski, N., Baranzini, A., \& Maradan, D. (2015). On scope effect in contingent valuation: does the statistical distribution assumption matter? HEG-Geneva Working papers, http://arodes.hes-so.ch/ record/683? $1 n=$ fr. 
Borzykowski, N., Baranzini, A., \& Maradan, D. (2017). Y a-t-il assez de réserves forestières en Suisse? Une évaluation contingente. Economie rurale, 359.

Bowes, M.D., \& Loomis, J.B. (1980). A note on the use of travel cost models with unequal zonal populations. Land Economics, 56(4), 465-470.

Cesario, F.J., \& Knetsch, J.L. (1976). A recreation site demand and benefit estimation model. Regional Studies, 10(1), 97-104.

Cho, S.-H., Bowker, J., English, D.B., Roberts, R.K., \& Kim, T. (2014). Effects of travel cost and participation in recreational activities on national forest visits. Forest Policy and Economics, 40, 21-30.

Clawson, M. et al. (1959). Methods of measuring the demand for and value of outdoor recreation. Resources for the Future.

Clawson, M., \& Knetsch, J.L. (1963). Outdoor recreation research: some concepts and suggested areas of study. Natural Resources Journal, 3, 250.

Creel, M.D., \& Loomis, J.B. (1990). Theoretical and empirical advantages of truncated count data estimators for analysis of deer hunting in California. American Journal of Agricultural Economics, 72(2), 434-441.

Englin, J.E., Holmes, T.P., \& Sills, E.O. (2003). Estimating forest recreation demand using count data models. In Forests in a market economy (pp. 341-359). Springer.

Feather, P., \& Shaw, W.D. (1999). Estimating the cost of leisure time for recreation demand models. Journal of Environmental Economics and Management, 38(1), 49-65.

Fezzi, C., Bateman, I.J., \& Ferrini, S. (2014). Using revealed preferences to estimate the value of travel time to recreation sites. Journal of Environmental Economics and Management, 67(1), 5870 .

FOEN (2014). Annuaire la forêt et le bois. Technical report, Schmutz A. and Gross D.

FOEN (2015). Qui paie pour des sentiers forestiers agréables? Technical report, Federal Office for the Environment.

FSO (2015). Statistik Schweiz. http://www.bfs.admin.ch/. Accessed:18.02.2015.

FSO (2016). L'économie forestière en Suisse, statistique de poche 2016.

Garcia, S., \& Jacob, J. (2010). La valeur récréative de la forêt en France: une approche par les coûts de déplacement. Revue d'Etudes en Agriculture et Environnement, 91(1), 43-71.

Greene, W.H. (1994). Accounting for excess zeros and sample selection in Poisson and Negative Binomial regression models. NYU working paper no. EC-94-10.

Haab, T.C., \& McConnell, K.E. (2002). Valuing environmental and natural resources: the econometrics of non-market valuation. Edward Elgar Publishing.

Heckman, J.J. (1979). Sample selection bias as a specification error. Econometrica: Journal of the Econometric Society, 153-161.

Lambert, D. (1992). Zero-inflated Poisson regression, with an application to defects in manufacturing. Technometrics, 34(1), 1-14.

Lamprecht, M., Fischer, A., \& Stamm, H. (2014). Sport Suisse 2014 activité et consommation sportives de la population suisse. Technical report, Sport Federal Office.

Long, J.S., \& Freese, J. (2014). Regression models for categorical dependent variables using Stata. Stata Press.

Loomis, J. (2006). A comparison of the effect of multiple destination trips on recreation benefits as estimated by travel cost and contingent valuation methods. Journal of Leisure Research, 38 (1), 46.

McConnell, K.E. (1992). On-site time in the demand for recreation. American Journal of Agricultural Economics, 74(4), 918-925.

OECD (2015). OECD stat. http://stats.oecd.org/index.aspx?r=882035. Accessed: 18.02.2015.

Ott, W., Baur, M., \& Thalmann, C.-L.S. (2005). Der monetäre Erholungswert des Waldes. FOEN.

Ovaskainen, V., Neuvonen, M., \& Pouta, E. (2012). Modelling recreation demand with respondentreported driving cost and stated cost of travel time: A Finnish case. Journal of Forest Economics, $18(4), 303-317$.

Parsons, G.R. (2003). The travel cost model. In A primer on nonmarket valuation (pp. 269-329). Springer.

Parsons, G.R., Wilson, A.J., et al. (1997). Incidental and joint consumption in recreation demand. Agricultural and Resource Economics Review, 26, 1-6.

Phaneuf, D.J., \& Smith, V.K. (2005). Recreation demand models. Handbook of Environmental Economics, 2, 671-761. 
SBB (2015). Plus de passagers et de marchandises, un résultat du groupe en recul, un nouveau bénéfice pour CFF Cargo au premier semestre 2014. http://www.cff.ch/groupe/medias/archives.newsdetail. 2014-9-0109_1.html. Accessed: 18.02.2015.

Shrestha, R.K., Seidl, A.F., \& Moraes, A.S. (2002). Value of recreational fishing in the Brazilian Pantanal: a travel cost analysis using count data models. Ecological Economics, 42(1), 289-299.

Smith, V.K., Desvousges, W.H., \& McGivney, M.P. (1983). The opportunity cost of travel time in recreation demand models. Land Economics, 259-278.

TCS (2015). Exemple de frais pour un véhicule. http://www.tcs.ch/fr/auto-mobilite/couts-de-la-voiture/ exemple.php. Accessed: 18.02.2015.

VOEV (2014). Tarif général des voyageurs. http://www.voev.ch/fr/ch-direct/Tarifs-et-Prescriptions/ Tarifs-actuels-du-SD. Accessed: 18.02.2015.

Von Grünigen, S., \& Montanari, D. (2014). Swiss forest recreation: monetary value and influencing factors. Schweizerische Zeitschrift für Forstwesen, 165(5), 113-120.

Willis, K.G., \& Garrod, G. (1991). An individual travel-cost method of evaluating forest recreation. Journal of Agricultural Economics, 42(1), 33-42.

Zandersen, M., \& Tol, R.S. (2009). A meta-analysis of forest recreation values in Europe. Journal of Forest Economics, 15(1), 109-130. 